\begin{abstract}
المستخلص

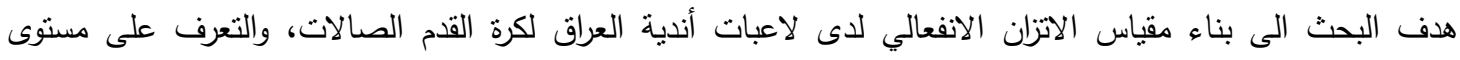

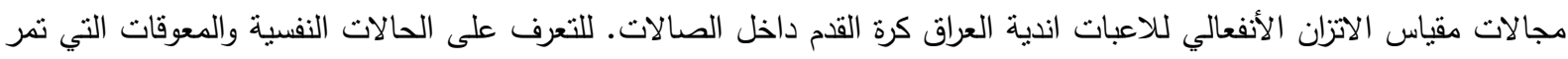
بها اللاعبة سواء كان ذلك في الوحدة التدريية او في المباريات، حيث ان الاساس هو انقان وتعلم المهارة بصورة دقيقة ورفع من مستوى اللاعبة ليس فقط بالناحية البدنية وانما بالناحية النفسية. واستخدمت الباحثان المنهج الوصفي بالاسلوب التحليلي، وتم اختيار

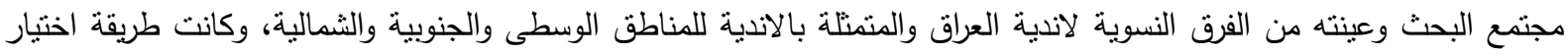

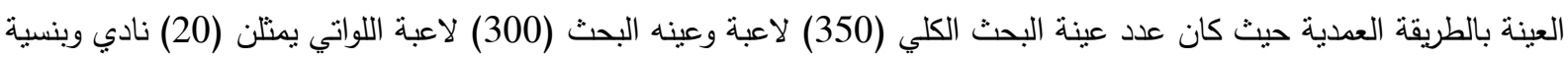
مئوية تبلغ (85.71\%) من مجتمع عينة البحث ونم نوزيع العينة الى اربعة انواع (عينة التجربة الاستطلاعية،عينة التجربة الرئيسية

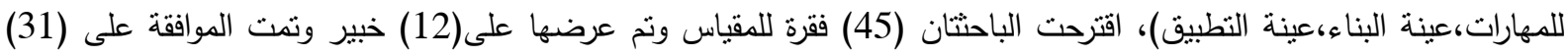

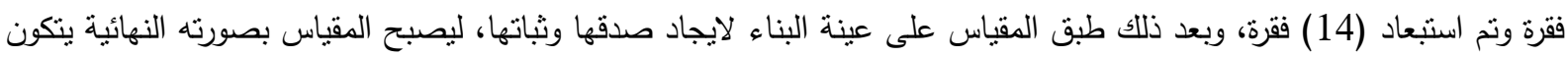

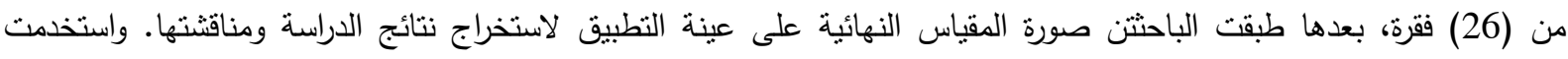

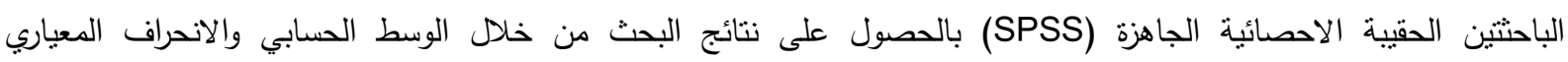
واختبار(t-test) للعينات المستقلة، واظهرت نتائج البحث معنوية بين الاتزان الانفعالي (العقلي، الاجتماعي، الحركي، الاستقرار

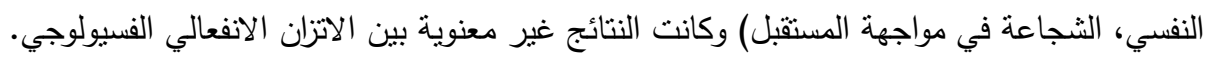

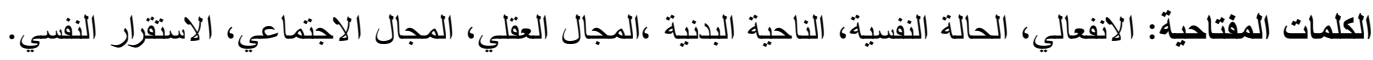

\title{
ABSTRACT Analytical study of Emotional Balance for Some Fundamental Skills in Iraqi Futsal Clubs
}

The research aimed at constructing emotional balance scale for Iraqi futsal clubs as well as identifying the level of emotional balance scale for Iraqi female futsal players. It also aimed at identifying the psychological and obstacles that female futsal player's face in training and during competition. The researchers used the descriptive method on (300) female futsal players who represent (20) clubs distributed as pilot study, main experiment, construction and applications subjects. The scale consisted of (26) item to come up with the rests. The data was collected and treated using SPSS to conclude that the results showed significance between emotional balance and mental, social, motor, psychological stability, and courage in facing the future.

Keywords: emotional, psychological state, physical aspect, mental, social and psychological stability.

(1) طالبة دراسات عليا (الدكتوره)، جامعة بغداد، كلية التربية البننية وعلوم الرياضة. (Teebasaleem1515@gmail.com)

Teeba Saleem Abdulmajeed, Post Graduate Student (Master), University of Baghdad, College of Physical Education and Sport Sciences, (Teebasaleem1515@gmail.com) (+96407716941051).

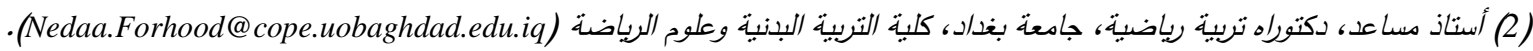
Nada Yasser, Assist Prof (PH.D), University of Baghdad, College of Physical Education and Sport Sciences, (Nedaa.Forhood@cope.uobaghdad.edu.iq) (+9647703995497). 
بدأ علماء النفس بالأهتمام بشكل كبير وتفصيلي بالناحية النفسية للاعبات والظروف المحيطة بهم وتحليل سلوكياتهم وردود الافعال وانفعالاتهم والعوامل المؤثرة فيها من أجل ايجاد الحلول المناسبة والمعالجة العلمية الصحيحة بلهية للاعبين وفق المواقف التي يمرون بها اذ ان اللاعبين في يومنا هذا ذو مستوى افضل مقارنة مع اللاعبين الذين لعبو كرة القدم في الماضي(Adams, 2012) واصبح من الواجب على المدرب عدم اغفال الجانب النفسي كونه عامل محرك لهون أساسي لسلوك اللاعبين ورغباتهم ، فكلما كانت أفكار اللاعبين ورغباتم باتجاه اللعبة وتحقق النجاح يحدث التطور والتقدم

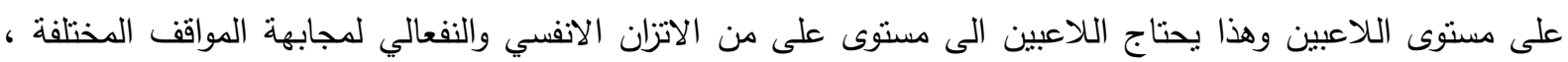

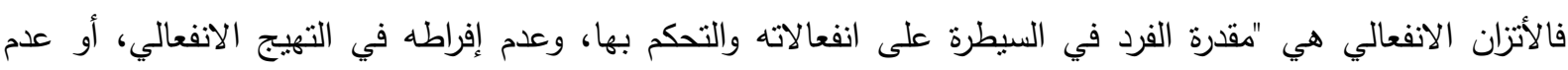

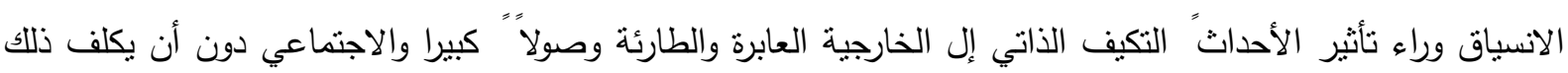
مجهودا (يونس، 2004). من هنا تاني أهمية البحث في التعرف على مستوى الاتزان الانفعالي لدى لاعبات الأندية

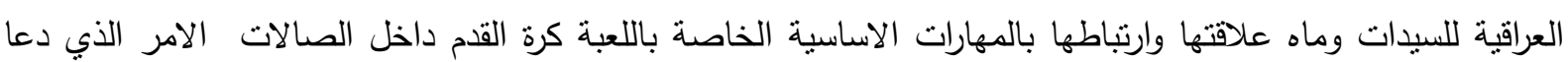
الباحثه الى الثروع بيناء مقياس خاص بالاتزان الانفعالي الذي يتلائم مع مستوى وطبيعة العينة لقياس هذا المتنغير

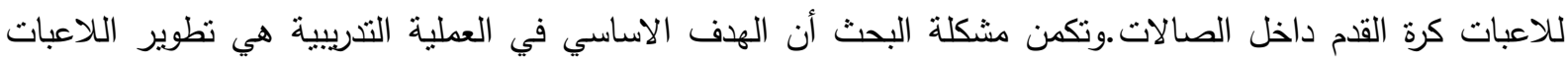
ومحاولة ايصال اللاعبة الى التكامل المهاري والبدني والنفسي و الوصول الى الاداء المهاري الجيد من خلال استخدام

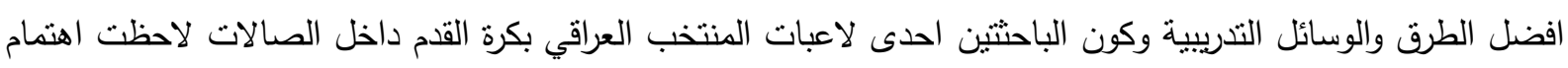

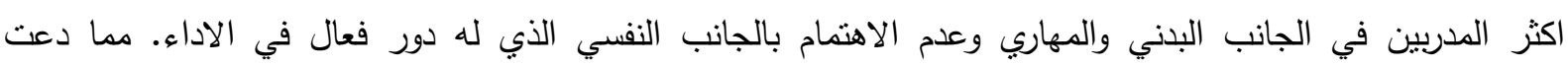

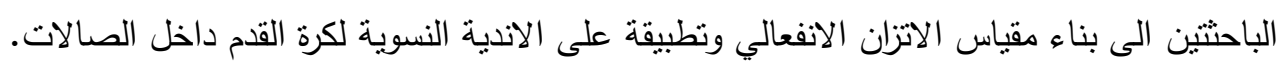

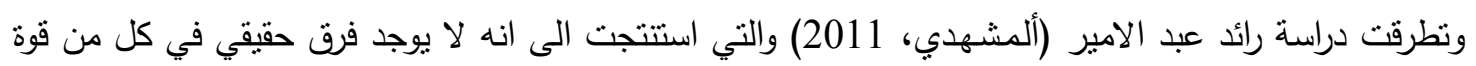

الأنا والاتزان الانفعالي ومستوى الطموح بين ناشئي الألعاب الفردية والفرقية. تطرقت دراسة (محمد موفق عبد الله الديوه جي، 2011) والتي استتنجت فاعلية مقياس الاتزان الانفعالي الذي نم تكييفه

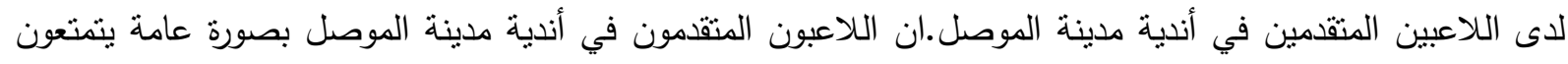
بدرجة عالية من الاتزان الانفعالي. وجود علاقة ايجابية ودالة إحصائيا بين كل من قوة الإرادة الرياضية الاتزان الانفعالي

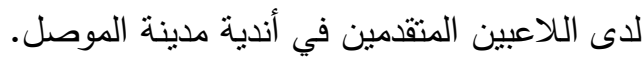
تطرقت دراسة (صدام محمد احمد،2013) والتي استتتجت ان التمرين على اهداف مختلفة وتمرينات التهديف على زوايا الاهداف الحقيقية وبصورة متدرجة يطور التهديف والمناولة والدقة، ان التمرينات المتنوعة تزيد من عامل الاثارة والنتويق التئ والمنافسة ولها الاثر البالغ في صفة الانسجام وروح التعاون والمثابرة مما ادى الى سهولة عملية نطوير القدرات الحركية والمهارات الاساسية لدى اللاعبين.

الطريقة والادوات:

استخدت الباحثتنان المنهج الوصفي بالاسلوب التحليلي لملائمته مع طبيعة المشكلة، إذ إنَّ المنهج الوصفي لا

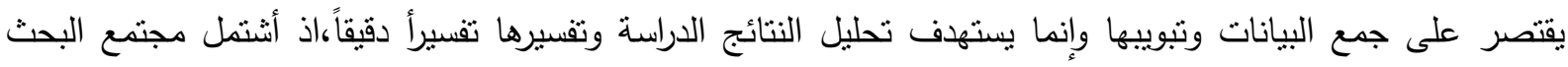
الكلي من لاعبات الفرق النسوية للأندية العراقية بكرة القدم الصالات والذي يبلغ عدهم عددهم (350)، بينما شملت عينة البحث (300) لاعبة اللواتي يمنلن (20) نادي وبنسبة مئوية نتلغ (85.71 \% من من مجتمع البحث الكلي، ونم توزيع العينة الى اربعة انواع هي (عينة التجربة الاستطلاعية،عينة التجربة الرئيسية للمهارات،عينة البناء،عينة التطبيق)، العينة

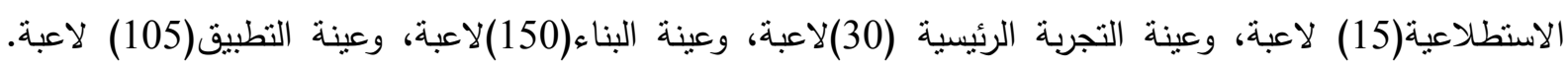
الجدول (1) يبين نوزيع العينة 


\begin{tabular}{|c|c|c|c|c|c|c|c|c|c|}
\hline P(E) & & & \multicolumn{7}{|c|}{ مجلة التربية الرياضية - المجلد (33) - العدد (3) - سنة 2021.} \\
\hline \multicolumn{7}{|c|}{ عينة البحث } & \multirow{2}{*}{\multicolumn{2}{|c|}{ 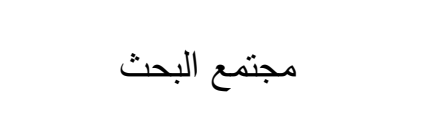 }} & \multirow{5}{*}{$ت$} \\
\hline \multirow{3}{*}{ 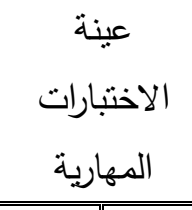 } & \multirow{3}{*}{\multicolumn{2}{|c|}{ 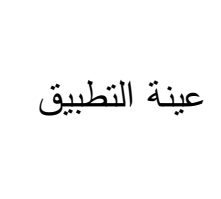 }} & \multirow{3}{*}{\multicolumn{2}{|c|}{ عينة البناء }} & \multirow{3}{*}{\multicolumn{2}{|c|}{ العينة استطلاعية }} & & & \\
\hline & & & & & & & \multirow{3}{*}{ اللاعبا } & \multirow{3}{*}{ اسم النادي } & \\
\hline & & & & & & & & & \\
\hline & $\%$ & 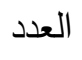 & $\%$ & 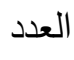 & $\%$ & 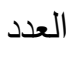 & & & \\
\hline & & 5 & & 10 & & & 15 & 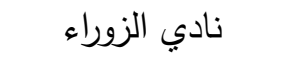 & 1 \\
\hline & & 5 & & 10 & & & 15 & ن ادي القوة الجوية & 2 \\
\hline & & & & 10 & & 5 & 15 & 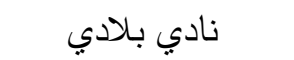 & 3 \\
\hline 5 & & & & 10 & & & 15 & نادي فتاة نينوى ل & 4 \\
\hline 5 & & & & 10 & & & 15 & 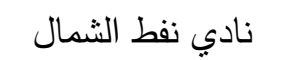 & 5 \\
\hline 5 & & & & 10 & & & 15 & نادي جومان & 6 \\
\hline 5 & & & & 10 & & & 15 & نادي غاز الشمال & 7 \\
\hline 5 & & & & 10 & & & 15 & نادي البلاي & 8 \\
\hline 5 & & & & 10 & & & 15 & نادي بابل & 9 \\
\hline & & & & 10 & & 5 & 15 & نادي سيروان & 10 \\
\hline & & 5 & & 10 & & & 15 & ن ل ن ادي شيخان & 11 \\
\hline & & 10 & & 10 & & & 15 & نادي عقرة & 12 \\
\hline & & 5 & & 10 & & & 15 & نادي تتاهي & 13 \\
\hline & & & & 10 & & & 15 & نادي شباب المستقبل & 14 \\
\hline & & 5 & & 10 & & & 15 & نادي فتاة دهوك & 15 \\
\hline & & 15 & & & & & 15 & نادي بيشمركة & 16 \\
\hline & & 15 & & & & & 15 & نادي حلبجة & 17 \\
\hline & & 15 & & & & & 15 & نادي شباب الوطن & 18 \\
\hline & & 15 & & & & & 15 & نادي شهربان & 19 \\
\hline & & 10 & & & & 5 & 15 & نادي افروديت & 20 \\
\hline 30 & & 105 & & 150 & & 15 & 300 & 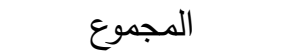 & -- \\
\hline
\end{tabular}

الأسس العلمية لبناء المقياس: لاستكمال خطوات بناء مقياس هذه الدراسة قامت الباحثين بعملية التحليل الاحصائي لفقرات المقياس، فمن خلال العملية الإحصائية ينم التأكد من توافر الثروط العلمية للمقياس وهي الصدق والثبات والموضوعية.

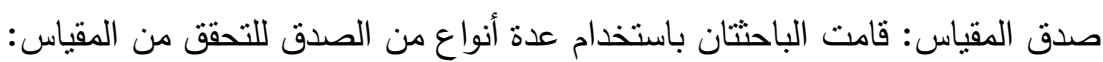

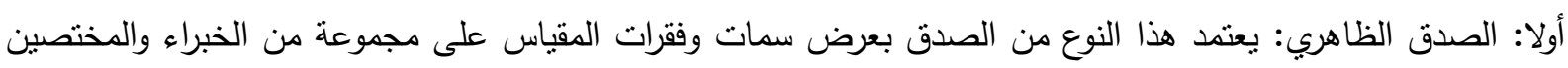

لتقدير صلاحيتها، وعلية قامت الباحث بعرض سمات وفقرات المقياس على عدد من الخبراء والمختصين للحكم عليها. ثانيا: الصدق المنطقي: قامت الباحثتين بتحقيق هذا النوع من الصدق لمقياس هذه الدراسة من خلال تعريف مفهوم الاتزان الانفعالي وتحديد سماتها وفقراتها بمساعدة مجموعة من الخبراء والمختصين. 


\section{مجلة التربية الرياضية - المجلد (33) - العدد (3) - سنة 2021.}

نالثاً: صدق البناء: ويتحقق هذا النوع من الصدق من خلال إجراء التحليل الإحصائي للعبارات، وقامت الباحثتين بالتحقق من خلال استخراج المؤشرات الآتية: 1- القوة التمييزية للفقرات: وللتحقق من ذلك اعتمدت الباحثتان أسلوب المجموعتين الطرفيتنين في حساب القدرة التمييزية للعبارات باستخدام اختبار (T-Test) للعينات المستقلة، وان الهدف من تحليل الفقرات هو الإبقاء على الفقرات ذات التمبيز

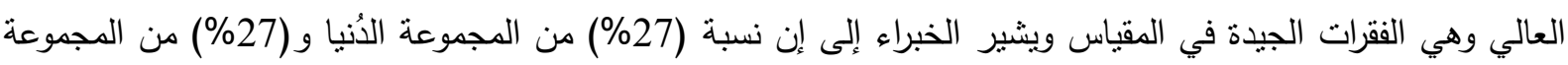
العُليا هي أفضل نسبة نحصل بواسطتها على اعلى معاملات التمييز لذا تم استخدام اختبار (T-Test) لدلالة فروق

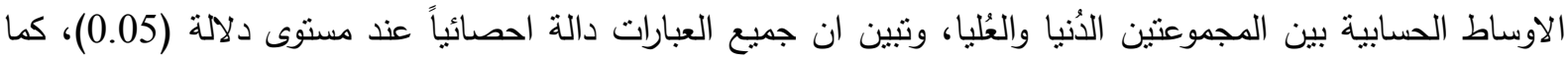

موضح في الجدول (2).

الجدول (2) يبين القوة التمييزية لفقرات بناء المقياس

\begin{tabular}{|c|c|c|c|c|c|c|c|}
\hline \multirow{2}{*}{ نوع الفرق } & \multirow{2}{*}{ الحقيقية } & \multirow{2}{*}{ قالمحسة ت } & \multicolumn{2}{|c|}{ المجموعة العليا } & \multicolumn{2}{|c|}{ المجموعة الدنيا } & \multirow{2}{*}{ رقم الفقرة } \\
\hline & & & $\varepsilon$ & س & $\varepsilon$ & س & \\
\hline معنوي & .000 & 15.238 & .94288 & 2.7561 & .00000 & 5.0000 & 1 \\
\hline معنوي & .000 & 25.111 & .49755 & 3.0488 & .00000 & 5.0000 & 2 \\
\hline معنوي & .000 & 29.376 & .00000 & 1.0000 & .72835 & 4.3415 & 3 \\
\hline معنوي & .000 & 60.723 & .00000 & 1.0000 & .40122 & 4.8049 & 4 \\
\hline معنوي & .000 & 31.492 & .47112 & 2.6829 & .00000 & 5.0000 & 5 \\
\hline معنوي & .000 & 24.611 & .81225 & 1.8780 & .00000 & 5.0000 & 6 \\
\hline معنوي & .000 & 26.080 & .57488 & 2.6585 & .00000 & 5.0000 & 7 \\
\hline معنوي & .000 & 30.959 & .70624 & 1.5854 & .00000 & 5.0000 & 8 \\
\hline معنوي & .000 & 44.823 & .47112 & 1.3171 & .21808 & 4.9512 & 9 \\
\hline معنوي & .000 & 53.268 & .00000 & 1.0000 & .44857 & 4.7317 & 10 \\
\hline معنوي & .000 & 23.218 & .67264 & 2.5610 & .00000 & 5.0000 & 11 \\
\hline معنوي & .000 & 18.473 & .57488 & 3.3415 & .00000 & 5.0000 & 12 \\
\hline معنوي & .000 & 55.318 & .43477 & 1.2439 & .00000 & 5.0000 & 13 \\
\hline معنوي & .000 & 15.173 & .86462 & 2.9512 & .00000 & 5.0000 & 14 \\
\hline معنوي & .000 & 47.361 & .40122 & 1.1951 & .30041 & 4.9024 & 15 \\
\hline معنوي & .000 & 48.795 & .00000 & 1.0000 & 48009 & 4.6585 & 16 \\
\hline معنوي & .000 & 55.318 & .00000 & 1.0000 & .43477 & 4.7561 & 17 \\
\hline معنوي & .000 & 24.484 & 63149 & 2.5854 & .00000 & 5.0000 & 18 \\
\hline معنوي & .000 & 38.013 & .59572 & 1.4634 & .00000 & 5.0000 & 19 \\
\hline معنوي & .000 & 24.997 & 63726 & 2.5122 & .00000 & 5.0000 & 20 \\
\hline معنوي & .000 & 17.901 & .47112 & 3.6829 & .00000 & 5.0000 & 21 \\
\hline معنوي & .000 & 54.128 & .30041 & 1.0976 & .33129 & 4.8780 & 22 \\
\hline معنوي & .000 & 15.675 & .78709 & 3.0732 & .00000 & 5.0000 & 23 \\
\hline
\end{tabular}




\begin{tabular}{|c|c|c|c|c|c|c|c|}
\hline \multicolumn{3}{|c|}{ (PJE) } & \multicolumn{5}{|c|}{ مجلة التربية الرياضية - المجلد (33) - العدد (3) - سنة 2021.} \\
\hline معنوي & .000 & 37.092 & .59367 & 1.5610 & .00000 & 5.0000 & 24 \\
\hline معنوي & .000 & 23.189 & .61287 & 2.7805 & .00000 & 5.0000 & 25 \\
\hline معنوي & .000 & 95.368 & .26365 & 1.0732 & .00000 & 5.0000 & 26 \\
\hline معنوي & .000 & 43.842 & .26365 & 1.0732 & .46065 & 4.7073 & 27 \\
\hline معنوي & .000 & 15.784 & $.00000^{\mathrm{a}}$ & 1.0000 & $.00000^{\mathrm{a}}$ & 5.0000 & 28 \\
\hline معنوي & .000 & 15.784 & .82121 & 2.9756 & .00000 & 5.0000 & 29 \\
\hline معنوي & .000 & 12.425 & .85469 & 3.3415 & .00000 & 5.0000 & 30 \\
\hline معنوي & .000 & 17.462 & .94804 & 2.4146 & .00000 & 5.0000 & 31 \\
\hline
\end{tabular}

معنوي اذا كانت قيمة المعنوية الحقيقة > 0,05 عند درجة حرية = 2- معامل الاتساق الداخلي: ويهدف الاتساق الداخلي الى التحقق من مدى تجانس الفقرات وانسجامها في دراسة الظاهرة المدروسة ولغرض التحقق من صدق المقياس باستخدام معامل الاتساق الداخلي قامت الباحثنين بالتعرف على مدى التى الارتباط بين درجة كل عبارة من عبارات المقياس والدرجة الكلية للمقياس باستخدام معامل الارتباط البسيط بيرسون. وتبين

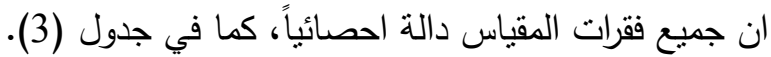
الجدول (3) يبين معامل الارتباط لعبارات المقياس مع الدرجة الكلية للمقياس

\begin{tabular}{|c|c|c|c|}
\hline 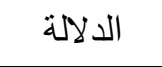 & المعنوية الحقيقية & معامل الإرتباط البسيط & رقم العبارة \\
\hline معنوي & .000 & $.493^{* *}$ & 1 \\
\hline معنوي & .000 & $.343^{* *}$ & 2 \\
\hline معنوي & .000 & $.633^{* *}$ & 3 \\
\hline معنوي & .000 & $.666^{* *}$ & 4 \\
\hline معنوي & .000 & $.536^{* *}$ & 5 \\
\hline 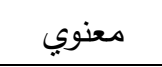 & .000 & $.493 * *$ & 6 \\
\hline معنوي & .047 & $.163 *$ & 7 \\
\hline معنوي & .000 & $.536 * *$ & 8 \\
\hline معنوي & .000 & $.565 * *$ & 9 \\
\hline معنوي & .000 & $.676^{* *}$ & 10 \\
\hline غير معنوي & .278 & .089 & 11 \\
\hline معنوي & .001 & $-.277-* *$ & 12 \\
\hline معنوي & .000 & $.431 * *$ & 13 \\
\hline معنوي & .013 & $-.202-*$ & 14 \\
\hline معنوي & .000 & $.544 * *$ & 15 \\
\hline معنوي & .000 & $.705 * *$ & 16 \\
\hline معنوي & .000 & $.560 * *$ & 17 \\
\hline غير معنوي & .286 & .088 & 18 \\
\hline معنوي & .000 & $.431 * *$ & 19 \\
\hline
\end{tabular}


مجلة التربية الرياضية - المجلد (33) - العدد (3) - سنة 2021.

\begin{tabular}{|c|c|c|c|}
\hline غير معنوي & .835 & -.017 & 20 \\
\hline معنوي & .005 & $.226^{* *}$ & 21 \\
\hline معنوي & .000 & $.560 * *$ & 22 \\
\hline معنوي & .001 & $.622 * *$ & 23 \\
\hline معنوي & .000 & $.466^{* * *}$ & 24 \\
\hline معنوي & .006 & $.224 * *$ & 25 \\
\hline معنوب & .000 & $.626 * *$ & 26 \\
\hline معنوي & .000 & $.571 * *$ & 27 \\
\hline معنوي & .000 & $.497 * *$ & 28 \\
\hline غير معنوي & .694 & -.032 & 29 \\
\hline غير معنوي & .412 & -.067 & 30 \\
\hline معنوي & .000 & $.343 * *$ & 31 \\
\hline
\end{tabular}

$80=0$ = 0,05 عندوي اذا كانت قيمة المعنوية الحقيقة حرية 3- الصدق العاملي: الصدق العاملي هو اختزال عدد مفردات المقياس الى اقل عدد، استخدم الباحث الصدق العامليه في في تحديد صدق فقرات المقياس كونه من اهم الوسائل التي تستخدم في تحديد صدق البناء او صدق التكوين الفرضي الذي يبدأ بحساب معاملات الارتباط بين درجات الفقرات بجدول بطلق عليه ( مصفوفة الارتباط)،تم ادخال(31)فقرة للتحليل العاملي من خلال محك(هنري كايزر) الذي يوقف استخراج العوامل التي يقل جذرها الكامن عن(1) وبينت نتائج التحليل

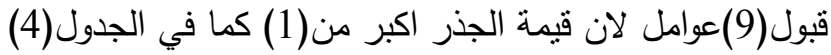

\begin{tabular}{|c|c|c|c|c|c|c|c|c|c|}
\hline \multicolumn{10}{|c|}{ عـــــرض مجمـــــوع التبـــــــــــن } \\
\hline \multirow[b]{2}{*}{ العوامل } & \multicolumn{3}{|c|}{ القيم الذاتية الأولية } & \multicolumn{3}{|c|}{ قبل التدوير } & \multicolumn{3}{|c|}{ بعد التذوير } \\
\hline & القيم العينية الكامن & اهمبة العوامل التباين & $\begin{array}{c}\text { التباين المتجمع التراكمية } \\
\text { \% }\end{array}$ & |القيم العينية الكامن|| & \% اهمبة العوامل التباين & $\begin{array}{c}\text { التباين المتجمع التراكمية } \\
\text { \% }\end{array}$ & 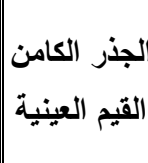 & | اهمية العوامل التباين & التباين المتجمع \\
\hline 1 & 7.727 & 24.927 & 24.927 & 7.727 & 24.927 & 24.927 & 6.444 & 20.787 & 20.787 \\
\hline 2 & 2.243 & 7.236 & 32.163 & 2.243 & 7.236 & 32.163 & 1.889 & 6.094 & 26.881 \\
\hline 3 & 1.815 & 5.856 & 38.019 & 1.815 & 5.856 & 38.019 & 1.830 & 5.902 & 32.783 \\
\hline 4 & 1.532 & 4.943 & 42.963 & 1.532 & 4.943 & 42.963 & 1.768 & 5.702 & 38.485 \\
\hline 5 & 1.361 & 4.391 & 47.354 & 1.361 & 4.391 & 47.354 & 1.667 & 5.377 & 43.862 \\
\hline 6 & 1.270 & 4.098 & 51.451 & 1.270 & 4.098 & 51.451 & 1.564 & 5.045 & 48.907 \\
\hline 7 & 1.183 & 3.815 & 55.267 & 1.183 & 3.815 & 55.267 & 1.459 & 4.706 & 53.613 \\
\hline 8 & 1.101 & 3.551 & 58.818 & 1.101 & 3.551 & 58.818 & 1.376 & 4.438 & 58.052 \\
\hline 9 & 1.092 & 3.522 & 62.340 & $\overline{1.092}$ & $\overline{3.522}$ & 62.340 & 1.329 & 4.288 & 62.340 \\
\hline 10 & .970 & $\mathbf{3 . 1 2 7}$ & 65.467 & & & & & & \\
\hline 11 & .884 & 2.851 & 68.319 & & & & & & \\
\hline 12 & 8.844 & 2.724 & 71.042 & & & & & & \\
\hline 13 & .801 & 2.585 & 73.627 & & & & & & \\
\hline 14 & $\begin{array}{l}.748 \\
\end{array}$ & 2.412 & 76.039 & & & & & & \\
\hline 15 & .696 & 2.247 & $\mathbf{7 8 . 2 8 6}$ & & & & & & \\
\hline 16 & .655 & 2.113 & 80.399 & & & & & & \\
\hline 17 & .622 & 2.006 & 82.404 & & & & & & \\
\hline 18 & .575 & 1.854 & 84.258 & & & & & & \\
\hline
\end{tabular}


مجلة التربية الرياضية - المجلد (33) - العدد (3) - سنة 2021.

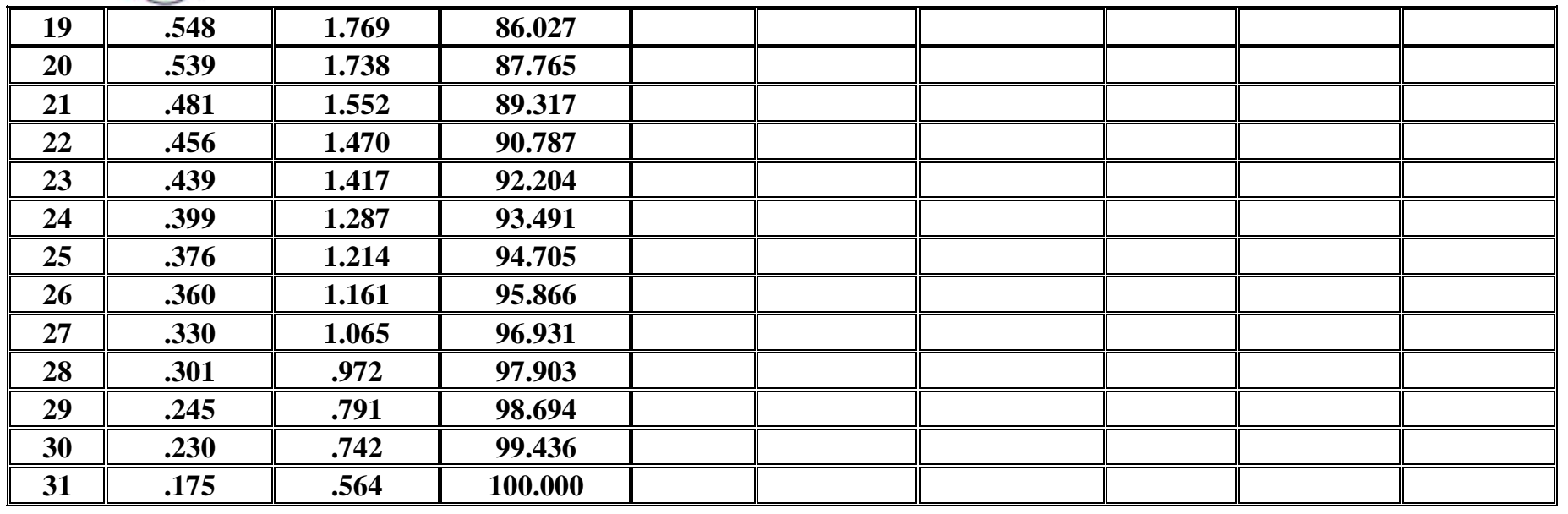

العوامل قبل التدوير : بين التحليل الاحصائي استخلاص(9)عوامل اولية ولانة لا يمكن تفسير هذه العوامل الا بعد تدويرها.

كما في الجدول رقم (5) - 20 - (5)

\begin{tabular}{|c|c|c|c|c|c|c|c|c|c|}
\hline \multirow{2}{*}{ رقم الفقرة } & \multicolumn{9}{|c|}{ العوامل } \\
\hline & 1 & 2 & 3 & 4 & 5 & 6 & 7 & 8 & 9 \\
\hline 1 & -.061- & .250 & $-.259-$ & .461 & -.286- & .125 & . 119 & -..165- & .443 \\
\hline 2 & $-.248-$ & .110 & .221 & .172 & .574 & .369 & $-.357-$ & - -.029- & $-.149-$ \\
\hline 3 & .803 & .012 & -.136- & 2.082 & -.159- & -.068- & .154 & .124 & .001 \\
\hline 4 & .736 & .048 & .175 & .155 & .107 & .008 & $-.076-$ & .091 & $-.154-$ \\
\hline 5 & $\begin{array}{l}-.454- \\
\end{array}$ & .323 & "-.148- & (.134 & .383 & . .185 & .252 & .221 & .250 \\
\hline 6 & .457 & .223 & .323 & .270 & $-.074-$ & .073 & $-.234-$ & $-.291-$ & $-.072-$ \\
\hline 7 & $-.145-$ & .382 & $-.327-$ & $-.035-$ & .462 & .202 & .306 & .082 & $-.033-$ \\
\hline 8 & .414 & .125 & .395 & .095 & $-.200-$ & -.036- & .068 & (.018 & .290 \\
\hline 9 & .644 & .177 & .015 & $-.122-$ & .020 & .026 & .221 & $-.057-$ & $-.153-$ \\
\hline 10 & .755 & .163 & .089 & -.139- & -.107- & 2.000 & .125 & .043 & -.076- \\
\hline 11 & -.092- & .482 & $-.326-$ & .003 & -.092- & $-.168-$ & $-.266-$ & -.019- & $-.120-$ \\
\hline 12 & $-.480-$ & $-.030-$ & .514 & .023 & $-.061-$ & .040 & .376 & $-.115-$ & .067 \\
\hline 13 & .413 & .395 & $-.172-$ & $-.257-$ & .070 & $-.046-$ & -.279 & $-.180-$ & .097 \\
\hline 14 & $-.495-$ & .115 & .413 & .103 & -.079 & -.078 & .279 & $-.110-$ & $-.027-$ \\
\hline 15 & .578 & .240 & $-.003-$ & -.196- & .124 & $-.136-$ & .137 & .289 & .068 \\
\hline 16 & .769 & .085 & .045 & .159 & -.042- & .027 & .062 & - -.079- & $-.175-$ \\
\hline 17 & .758 & $-.042-$ & $-.158-$ & $-.116-$ & .040 & .118 & .002 & .174 & $-.030-$ \\
\hline 18 & -.245 & .319 & .159 & .592 & .156 & $-.290-$ & $-.051-$ & $-.077-$ & $-.301-$ \\
\hline 19 & .375 & .088 & .028 & .155 & $-.151-$ & .614 & $-.185-$ & $-.206-$ & .103 \\
\hline 20 & $-.334-$ & .404 & $-.180-$ & .374 & .011 & $-.358-$ & .157 & .022 & .028 \\
\hline 21 & .103 & .000 & .514 & .047 & -.096- & .116 & -.106- & .523 & .060 \\
\hline 22 & .712 & .134 & $-.018-$ & . .024 & .033 & - -204- & .025 & $-.102-$ & -.067- \\
\hline 23 & $-.447-$ & .250 & $-.085-$ & $-.001-$ & $-.256-$ & .448 & .152 & .195 & $-.150-$ \\
\hline 24 & .359 & .159 & .385 & -.118 & .348 & -.228 & $-.074-$ & .063 & .214 \\
\hline 25 & $-.217-$ & .639 & .055 & $-.189-$ & $-.303-$ & -.014- & $-.102-$ & .246 & $-.113-$ \\
\hline 26 & .676 & .033 & .128 & .004 & .195 & .054 & .236 & $-.110-$ & $-.013-$ \\
\hline 27 & .543 & 2.219 & -.157- & .242 & -.146- & 2.065 & -.116- & .183 & .166 \\
\hline 28 & .646 & $-.198-$ & .011 & .385 & .100 & .123 & .109 & .197 & .006 \\
\hline 29 & $-.412-$ & .331 & .270 & -.149 & .017 & $-.096-$ & $-.313-$ & .130 & .373 \\
\hline
\end{tabular}


(PJE)

مجلة التربية الرياضية - المجلد (33) - العدد (3) - سنة 2021.

\begin{tabular}{|c|c||c|c|c||c|c|c|c|c|}
\hline 30 & $-.394-$ & .307 & .168 & $-.074-$ & $-.215-$ & .113 & .059 & .114 & $-.488-$ \\
\hline \hline 31 & .165 & .497 & .181 & $-.411-$ & .045 & .140 & .214 & $-.419-$ & .077 \\
\hline
\end{tabular}

العوامل بعد التدوير : استخدام التدوير المتعامد بأسلوب (الفاريماكس) (لهنري كايزر)، إذ يعد هذا الاسلوب من افضل

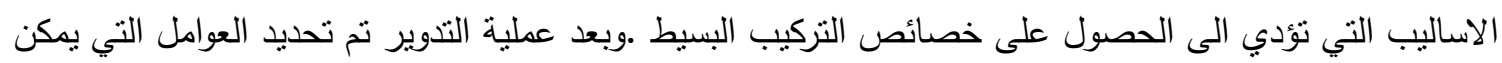
تفسيرها بالاعتماد على درجة تتبع الفقرات ضمن عواملها وعدد الفقرات في كل عامل إذ نم اعتماد درجة النتبع (0.30)

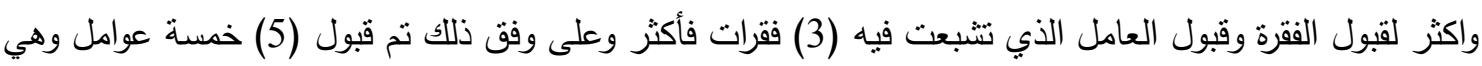

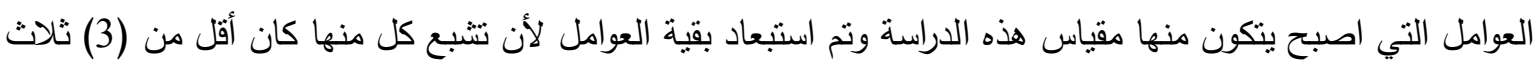
فقرات. كما في الجدول رقم) (6)

\begin{tabular}{|c|c|c|c|c|c|c|c|c|c|}
\hline \multirow{2}{*}{ رقم الفقرة } & \multicolumn{9}{|c|}{ العوامل } \\
\hline & 1 & 2 & 3 & 4 & 5 & 6 & 7 & 8 & 9 \\
\hline 16 & .775 & & & .012 & -.187- & & & .082 & .087 \\
\hline 3 & .772 & & & -.096- & -.106- & & & .141 & $-.224-$ \\
\hline 10 & ב.744 & & & -.149- & $-.129-$ & & & - -.011- & -.104- \\
\hline 4 & .727 & & & $\begin{array}{l}.006 \\
\end{array}$ & $-.160-$ & & & $-.049-$ & .206 \\
\hline 26 & 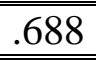 & & & $\begin{array}{c}-.100- \\
\end{array}$ & 0.032 & & & $\begin{array}{l}-.015- \\
\end{array}$ & $\begin{array}{l}.076 \\
\end{array}$ \\
\hline 9 & .683 & & & -.086- & .003 & & & -.056- & $-.053-$ \\
\hline 17 & 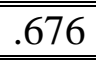 & & & -.315- & $\begin{array}{l}.001 \\
\end{array}$ & & & $\begin{array}{c}-.018- \\
\end{array}$ & $\begin{array}{l}.030- \\
\end{array}$ \\
\hline 22 & .665 & & & .090 & -.150- & & & $-.020-$ & $-.064-$ \\
\hline 28 & .659 & & & $-.074-$ & .000 & $-.373-$ & & .164 & .126 \\
\hline 15 & .584 & & & -.072- & . .177 & & & $-.129-$ & $-.198-$ \\
\hline 27 & .486 & & & .011 & $-.023-$ & & & .268 & -.019- \\
\hline 6 & .420 & & & .174 & -.375- & & & 2.214 & .374 \\
\hline 12 & & -.719 & & $\begin{array}{c}.078 \\
\end{array}$ & $\begin{array}{c}.020 \\
\end{array}$ & & & -.004- & $\begin{array}{l}-.012- \\
\end{array}$ \\
\hline 14 & & $-.560-$ & & 2.277 & .005 & & & $-.008-$ & -.019- \\
\hline 13 & & .512 & & $-.026-$ & $-.023-$ & & & .039 & .045 \\
\hline 11 & & .486 & & .037 & .044 & & & $\begin{array}{c}.061 \\
\end{array}$ & $\begin{array}{l}.049- \\
\end{array}$ \\
\hline 30 & & & .682 & . .177 & $-.008-$ & & & -.189- & .075 \\
\hline 25 & & & .652 & .183 & .059 & & & .022 & $-.123-$ \\
\hline 23 & & & .639 & $-.095-$ & .252 & & & 197 & .045 \\
\hline 18 & & & & 002 & 2.001 & & & -.001- & .261 \\
\hline 20 & & & & . .158 & .252 & & & .172 & -.194- \\
\hline 77 & & & & .094 & .143 & & & -.029- & .093 \\
\hline 5 & & & & .151 & .735 & & & .151 & .078 \\
\hline 31 & & & & -.090- & . 108 & .801 & & .033 & .028 \\
\hline 21 & & & & -.133- & -.104- & & .598 & -.054- & .117 \\
\hline 29 & & & & .103 & .045 & & .578 & 0.048 & .043 \\
\hline 24 & & & & .065 & .024 & & .495 & $-.203-$ & .097 \\
\hline 8 & & & & -.025- & $-.222-$ & & .403 & .256 & -..063- \\
\hline 1 & & & & $\begin{array}{c}.191 \\
\end{array}$ & .110 & & & .281 & $\begin{array}{l}-117- \\
\end{array}$ \\
\hline 19 & & & & $-.128-$ & $-.135-$ & .449 & & 2.491 & .427 \\
\hline 2 & & & & 0.080 & .228 & & & $-.143-$ & .797 \\
\hline
\end{tabular}

تفسير العوامل: بعد التدوير (5) عوامل تضم (26) فقرة وقامت الباحثتين بترتيب الفقرات ضمن كل عامل،كما في الجدول 


\begin{tabular}{|c|c|c|c|c|c|c|c|c|c|c|}
\hline (PJE) & & & & & سنة 1 & لعدد (3) & (33) & ية - المه & الريا & مجلة الن: \\
\hline لخامس & العامل & الرابع & & ثالث & العامل & لثاني & & الاول & & \\
\hline التثبع & الفقرة & التثبع & الفقرة & التثبع & الفقرة & التشبع & الفقرة & التُشبع & الفقرة & \\
\hline 0.598 & 21 & 0.449 & 19 & 0.682 & 30 & $0.719-$ & 12 & 0.775 & 16 & .1 \\
\hline 0.578 & 29 & 0.801 & 31 & 0.652 & 25 & $0.560-$ & 14 & 0.772 & 3 & .2 \\
\hline 0.495 & 24 & - $0.373-$ & 18 & 0.639 & 23 & 0.512 & 13 & 0.744 & 10 & .3 \\
\hline 0.403 & 8 & & & & & 0.486 & 11 & 0.727 & 4 & .4 \\
\hline & & & & & & & & 0.688 & 26 & .5 \\
\hline & & & & & & & & 0.683 & 9 & .6 \\
\hline & & & & & & & & 0.676 & 17 & .7 \\
\hline & & & & & & & & 0.665 & 22 & .8 \\
\hline & & & & & & & & 0.659 & 28 & .9 \\
\hline & & & & & & & & 0.584 & 15 & .10 \\
\hline & & & & & & & & 0.486 & 27 & .11 \\
\hline & & & & & & & & 0.420 & 6 & .12 \\
\hline
\end{tabular}

ثنات المقياس: ان المقياس الجيد هو المقياس الذي يتصف بالثبات، وعلية قامت الباحثنين بالتأكد من اتصاف المقياس بالثبات من خلال استخدام الآتي: اولاً: معامل الفاكرونباخ: قامت الباحثتين بالتأكد من ان العبارات مترابطة من خلال استخدام استخراج معامل الفاكرونباخ باستخدام الحقيبة الإحصائية (spss). وتبين عند نطبيق هذا المعامل على عينة البناء والبالغة (150) لاعبة ان معامل

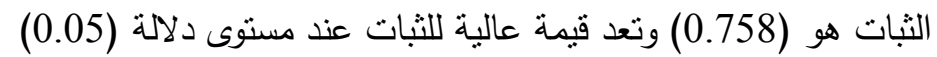
ثنانياً: طريقة التجزئة النصفية: نم من خلال هذه الطريقة ايجاد الثبات بطريقة التجزئة النصفية كانت بقيمة (684. ولكون هذا الارتباط يثير الى نصف العدد من الفقرات لذلك عدد الباحثنين لإيجاد معامل الارتباط الكلي عن طريق استخدام معادلة التصحيح او ما تسمى معادلة التتبؤ لسبيرمان (اذ اصبح الارتباط الكلي او معامل التصحيح بقيمة 
الجدول(8) يبين الوسط الحسابي والانحراف المعياري وقيمة (ت) المحسوبة والمعنوية الحقيقية ونوع الفرق للاعبات كرة القدم للصالات في المجال الاول(العقلي)

\begin{tabular}{|c|c|c|c|c|c|}
\hline نوع الفرق & الحقيقية & قالمحسة (ت) & الالمعباري & الوسط الحسابي & المتغيرات \\
\hline معنوي & 0.000 & -4.872 & 2.40364 & 4.8571 & الاستمارة \\
\hline
\end{tabular}

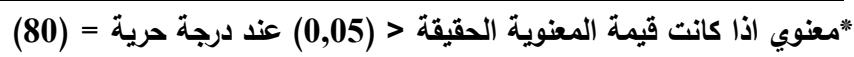

الجدول(9) يبين الوسط الحسابي والانحراف المعياري وقيمة (ت) المحسوبة والمعنوية الحقيقية ونوع الفرق للاعبات كرة القدم للصالات في المجال الثاني(الفسيولوجي)

\begin{tabular}{|c|c|c|c|c|c|}
\hline نوع الفرق & الحقنقية & قالمحة (ت) & الانحراف المعياري & الوسط الحسابي & المتغيرات \\
\hline غير معنوي & .981 & $-.023-$ & 4.19133 & 11.9905 & الاستمارة \\
\hline
\end{tabular}

الجدول(10) يبين الوسط الحسابي والانحراف المعياري وقيمة (ت) المحسوبة والمعنوية الحقيقية ونوع الفرق للاعبات كرة القدم للصالات في المجال الثالث(الحركي)

\begin{tabular}{|c|c|c|c|c|c|}
\hline نوع الفرق & الحقيقية & قلمة (ت) & الانحراف & الوسط الحسابي & المتغيرات \\
\hline معنوي & 0.000 & 13.415 & 2.8589 & 18.7429 & الاستمارة \\
\hline
\end{tabular}

الجدول(11) يبين الوسط الحسابي والانحراف المعياري وقيمة (ت) المحسوبة والمعنوية الحقيقية ونوع الفرق للاعبات كرة القدم للصالات في المجال الرابع(الاجتماعي)

\begin{tabular}{|c|c|c|c|c|c|}
\hline نوع الفرق & الحقيقية & قالمحسة (ت) & الانعراف & الوسط الحسابي & المتغيرات \\
\hline معنوي & 0.000 & 7.788 & 3.1828 & 17.419 & الاستمارة \\
\hline
\end{tabular}

الجدول(12) يبين الوسط الحسابي والانحراف المعياري وقيمة (ت) المحسوبة والمعنوية الحقيقية ونوع الفرق للاعبات كرة

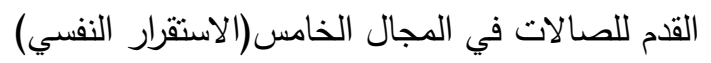

\begin{tabular}{|c|c|c|c|c|c|}
\hline نوع الفرق & الحقنقية & المحسة (ت) & الانحراف المعياري & الوسط الحسابي & المتغيرات \\
\hline معنوي & .018 & 2.395 & 2.56680 & 9.6000 & الاستمارة \\
\hline
\end{tabular}


الجدول(13) يبين الوسط الحسابي والانحراف المعياري وقيمة (ت) المحسوبة والمعنوية الحقيقية ونوع الفرق للاعبات كرة

القدم للصالات في المجال السادس(الثجاعة في مواجةة المستقبل)

\begin{tabular}{|c|c|c|c|c|c|}
\hline نوع الفرق & الحقيقية & قالمحسوبة (ت) & الالنحراف & الوسط الحسابي & المتغيرات \\
\hline معنوي & 0.000 & 12.515 & 2.5032 & 18.0571 & الاستمارة \\
\hline
\end{tabular}

المناقشة:

بناءً على بيانات الدراسة تعرض الباحثنين النتائج التي تم الحصول عليها من استمارات الاستبانة بعد تفريغها وإجراء المعالجات الإحصائية لها، وعلى وفق تسلسل المجالات والفقرات ومن ثمّ مناقتنها على وفق التسلسل في أدناه،نلاحظ مما تقام ان نتائج محاور مقياس الاتزان الانفعالي للاعبات كرة القدم الصالات في العراق اغلبها ذو فروق معنوية وهذا يدل على ان اهمية الاتزان الانفعالي لدى لاعبات كرة القدم الصالات في العراق اذ نلاحظ ان محاور الاتزان الانفعالي العقلي ، ، الاتزان الانفعالي الحركي ، الاتزان الانفعالي الاجتماعي ، الاستقرار النفسي و الثجاعة في مواجهة المستقبل جميعها ذو فروق معنوية ماعدا الاتزان الانفعالي الفسيولوجي والذي تتسبة الباحثتين الى ان ذلك يتاثر بالحالة الانية اللاعبة داخل الملعب، في الجدول(8) وترى الباحثتان ان الاتزان الانفعالي العقلي يعبر عما تشعر به اللاعبة اثثاء الاداء فكلما كانت اللاعبة في وضع اتزان انفعالي جيد كان لها تركيز والقدرات العقلية تعمل بالثي الذي يخدم اللاعبة في اداء مهاري جيد سواء كانت داخل الملعب او خارجه اثثاء اداء التمارين الخاصة بكرة القدم صالات. وايضا ان الانفعال يقلل من قدرة الثخص على النقد وإصدار الأحكام الصحيحة، كما لا يتيح له الهدوء والتأمل اللازمين للتفكير السليم كما

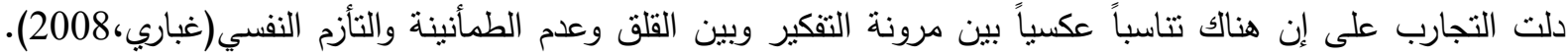
في الجدول(9) ان الاتزان الإنفعالي الفسيولوجي يحقق الصحة النفسية، ( ويتسم الثخص ذو الصحة النفسية بالإتزان الإنفعالي والثبات الوجداني واستقرار الاتجاهات ونضج الانفعالات ، وتعني وجود حالة من التمانل بين شدة الانفعال

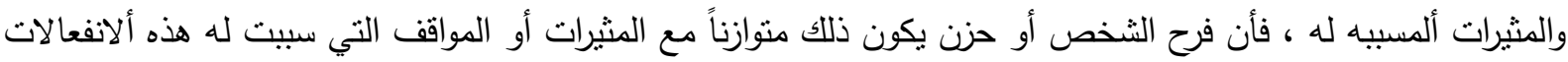

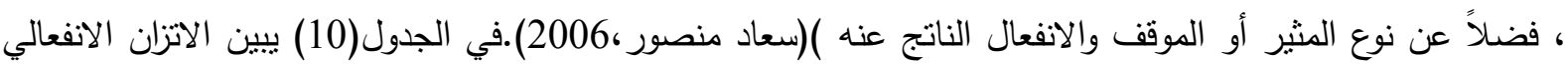

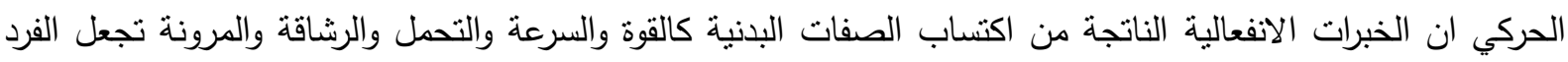
يحس بقدر معين من التقوق والامتياز لتوافر القدرة لديه على أداء الأنشطة الرياضية التي تحتاج إلى المزيد من القوة والسرعة والتحمل والتي لا يستطيع الكثيرون القيام بها.في الجدول(11) يبين الاتزان الانفعالي الاجتماعي فالفرد المتزن إنفعالياً هو القادر على إتخاذ قراراته بنفسه وهو شخص فاعل ومتفاعل في مجتمعه وبين جماعته، قادر على تحمل المسؤولية والتي تجمع في مضمونها كل مايصدر عن الثخص من سلوكيات عليه أن يتحمل عواقبها فالمسؤولية

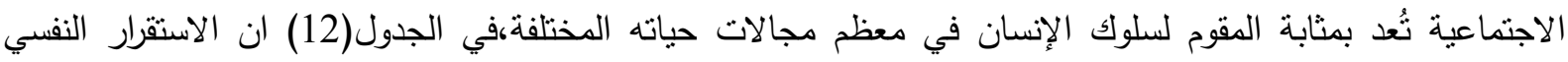
ويحدث عندما يصل الفرد إلى التتسيق، والموازنة بين خبرات ذاته،وعلاقته ببعض عوامله منانه منه اقصادية او بيئية لاهميته لاى الفرد.(ادللر الزبيدي،1999). في الجدول(13) عدم الوصول إلى المستوى المطلوب وخاصةً عند مواجهة خصم قوبي

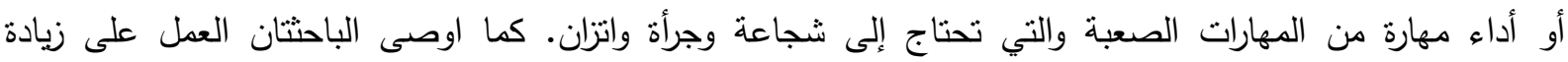
البطولات والمنافسات الخاصة فرق النسوية من أجل زيادة الخبرات الثخصية لدى اللاعبات. واستخدام مقياس الاتزان 
المصادر

Adams, P. (2012). Kick - off! The story of football. In P. Adams, Kick - off! The story of footbal (p. 50). Macmillan Heinemann. ادللر الزبيدي كامل والثميري جاسم قاص، (1999)،علم النفس التوافق، دار كتب لطابعه كثير موصل.

ألمشهدي، ر. ع .(2011) .قوة الأنا وعلاقتها بالاتزان الانفعالي ومستوى الطموح لاى ناشئي الألعاب الفردية

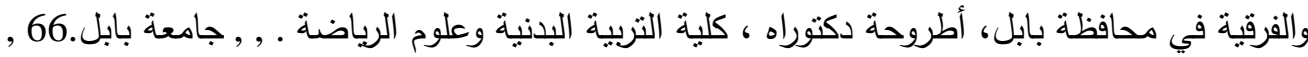
سعاد منصور غيث : الصحة النفسية للطفل ، ط1 ، عمان ، دار صفاء للنشر والتوزيع ، 2006 ـ صدام محمد(2013) تأثثر تمرينات خاصة بمساحات لعب مصغرة في تطوير بعض القدرات الحركية والمهارات الاساسية للاعبي الصالات بكرة القدمجامعة ديالى،كلية التربية الاساسية.

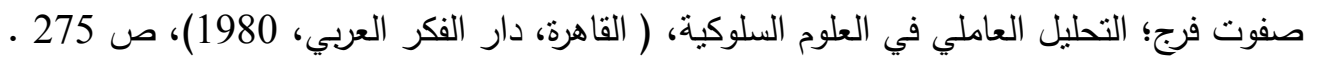
•باري، ثائر وآخرون (2008): علم النفس العام ، ط1، عمان، الأردن، مكتبة المجتمع العربي.

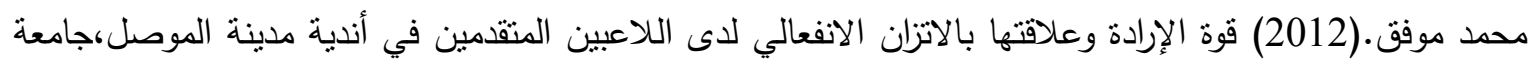
الموصل، كلية التربية الاساسية.

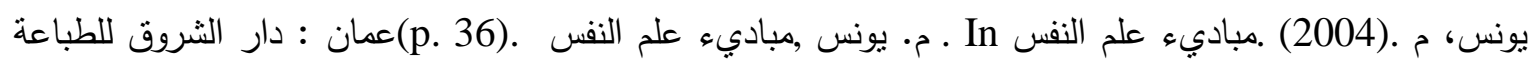
والثنر والتوزيع. 


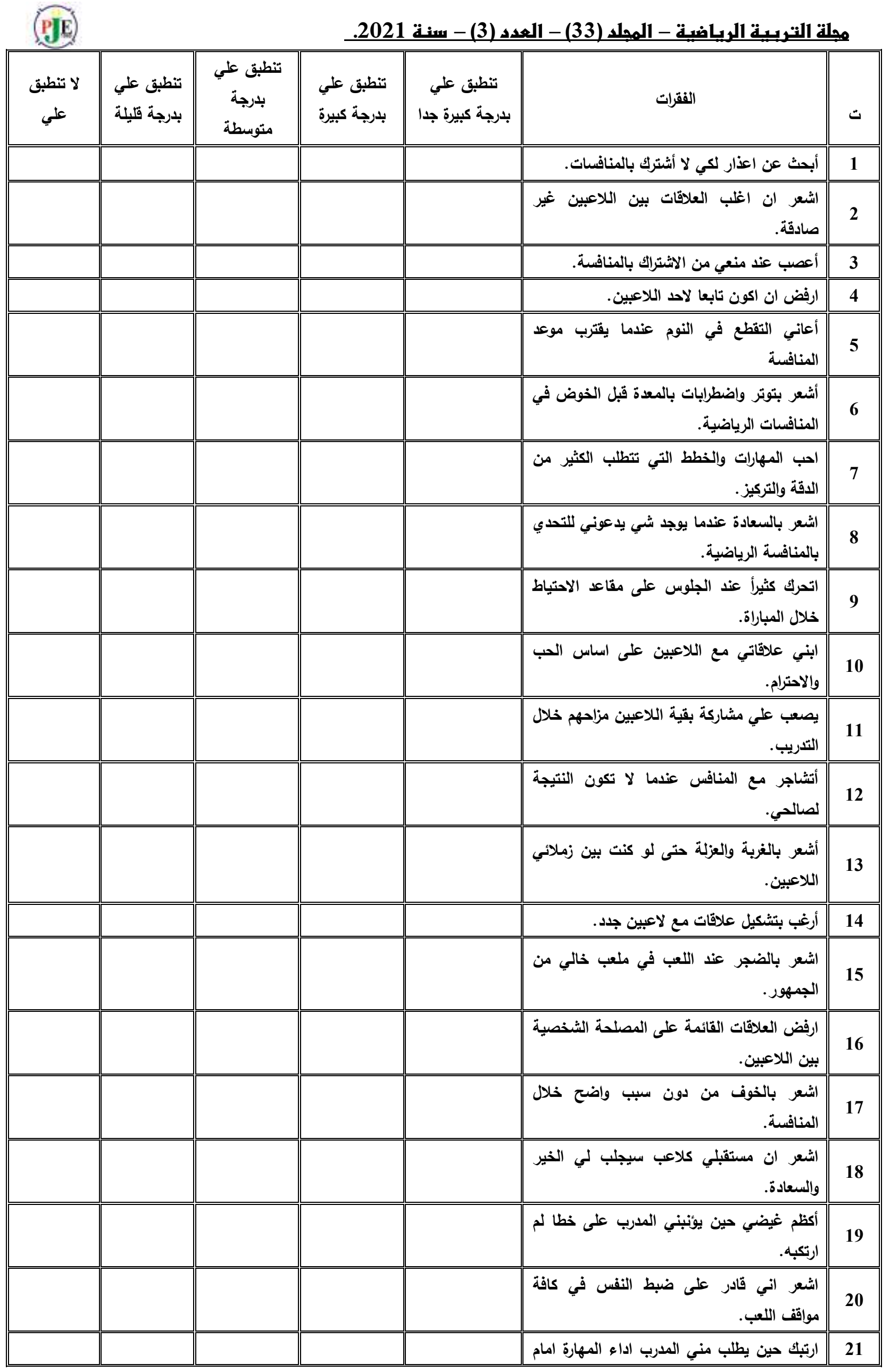




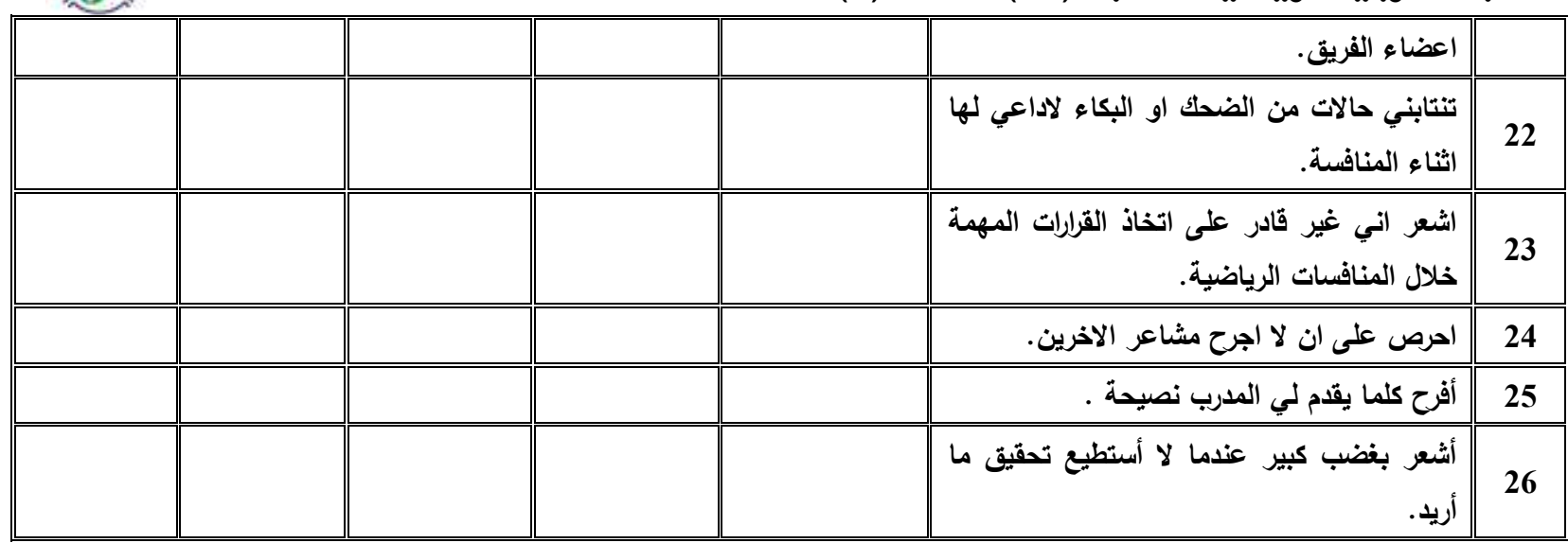

